\title{
Report on the Inaugural International Conference on Obesity and Chronic Diseases (ICOCD-2016)
}

\section{Andrea Mario Pompeo Romani}

Case Western Reserve University, 10900 Euclid Ave, Cleveland, OH 44106, USA

Correspondence to:

Dr. Andrea Mario Pompeo Romani

Case Western Reserve University

10900 Euclid Ave, Cleveland, OH 44106, USA

Tel: 1-216-3681625

E-mail: amr5@case.edu

Received: September 15, 2016

Accepted: October 17, 2016

Published: October 18, 2016

Citation: Romani AMP. 2016. Report on the Inaugural International Conference on Obesity and Chronic Diseases (ICOCD-2016). J Obes Chronic Dis 1(1): 4-5.

Copyright: (C) 2016 Romani AMP. This is an Open Access article distributed under the terms of the Creative Commons Attribution 4.0 International License (CC-BY) (http://creativecommons.org/ licenses/by/4.0/) which permits commercial use, including reproduction, adaptation, and distribution of the article provided the original author and source are credited.

Published by United Scientific Group

\section{Meeting Report}

Obesity is now recognized as one of the most important public health problems facing the world today, and the related chronic diseases are the primary cause of mortality, morbidity, disability and discrimination in health care, education and employment. Taking this into consideration, United Scientific Group (USG) held its first conference on Obesity. The International Conference on Obesity and Chronic Diseases was held from July 25-27, 2016 at Hampton Inn Tropicana, Las Vegas, USA (ICOCD-2016). The summit focused to "Discuss Link of Childhood and Adult Obesity to Other Chronic Diseases".

The conference started in the city of light, Las Vegas with the keynote presentation from Prof. Reza Hakkak (Chairman of ICOCD-2016), University of Arkansas for Medical Sciences (UAMS), USA. He delivered a lecture on "The Role of Obesity and Gut Microbiota on Cancer Promotion". He is a well-known nutritionist and researcher, who is also the Chairman of the Department of Dietetics and Nutrition in the College of Health Profession at UAMS. It was then followed by keynote lectures from Dr. Andrea Romani and Dr. Christopher Jenkinson.

Day one continued with a special session on "Nutrition and Obesity Grant Opportunities through USDA and NIH" by Dr. Deirdra N. Chester from National Institute of Food and Agriculture, USA and Dr. Tanya Agurs-Collins from National Cancer Institute/NIH/DHHS, USA which was well appreciated by all the participants of the conference. Post lunch, the discussion continued on "Childhood Obesity: Treatment and Prevention" with 9 potential speakers. The conference has delivered 38 poster presentations by attendees from all around the world. The posters were evaluated in terms of Coherence, Awareness of Previous Work, Attractiveness, Self-Explanatory, Text Visuals, and Overall Impression by the judges. Ms. Hiteshi Dhami-Shah from India has been awarded First Prize for Poster Grant, while Ms. Laura Yareni Zuniga from Mexico stood second in the Best Student Poster Grant Award. The welcome reception at the end of day gave attendees ample opportunity to network.

Day two of the conference started with an interactive session on "Molecular Medicine and Functional Genomics of Energy Metabolism and Chronic Diseases" by Prof. Jonny St. Amand from University Laval, Canada; delegates got an insight about the genetics of obesity. The discussion proceeded to debate the link of other chronic diseases with obesity and the role of inflammation under those conditions by 13 speakers after lunch. The session concluded after some lively discussions by the delegates.

Day three of the summit mainly focused on treatment and prevention methods of obesity. Nearly 30 attendees shared their research work and the methods to prevent or counteracts obesity. The session begun with an overview of the changes in liver metabolic profile and the involvement of antioxidant mechanism by Prof. 
Stepan B. Melnyk from University of Arkansas for Medical Sciences, and continued with highlights of the beneficial effects of bile acid therapy, beta-glucans ingestion and the beneficial effects of other natural source dietary compounds in counteracting the negative systemic effects of obesity and the occurrence of later-stage chronic diseases associated with it. The session continued with the short- and long-term beneficial effects of different bariatric surgery techniques and with follow-up approaches aiming at maintaining a healthy life-style after surgery. The session concluded after a lively discussion by the delegates. The conference has provided the platform for Feel Good Incorporation, USA to exhibit their products and services.

Overall, the meeting was well received and attended, promoting a lively interaction among the attendees and fostering several potential interactions. This level of success has encouraged the organizing committee to start preparing for a second edition of the International Meeting on Obesity and Chronic Diseases to be held in the summer 2017. The focus of the new summit is currently under consideration.

The conference was attended by around 120 delegates from 25 different countries. The majority of participants (50) came from USA, the top five were USA (50), Korea (11), Mexico (9), Brazil (8) and Canada (8). Figure 1 shows the breakdown of conference attendees, country-wise. We have

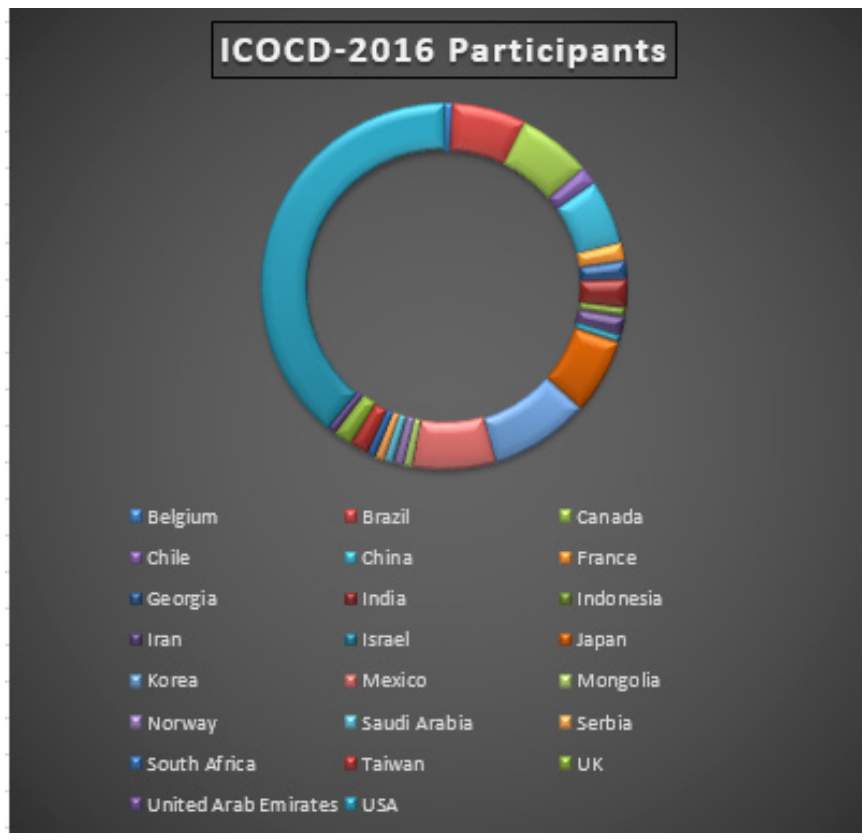

Figure 1: Country-wise participants of ICOCD-2016.

also received international delegates from many developing countries to showcase their research work at the summit. The proceeding of the conference will be published in the Journal of on Obesity and Chronic Diseases (JOCD). 